\title{
BMJ Open Development of consumer information leaflets for deprescribing in older hospital inpatients: a mixed- methods study
}

\author{
Natali Jokanovic (D , , ${ }^{1,2}$ Parisa Aslani, ${ }^{3}$ Sophie Carter, ${ }^{1,2}$ Mai Duong, ${ }^{1,2}$ \\ Danijela Gnjidic, ${ }^{3,4}$ Jesse Jansen, ${ }^{5}$ David Le Couteur, ${ }^{6,7}$ Sarah Hilmer ${ }^{1,2}$
}

To cite: Jokanovic N, Aslani P, Carter S, et al. Development of consumer information leaflets for deprescribing in older hospital inpatients: a mixedmethods study. BMJ Open 2019;9:e033303. doi:10.1136/ bmjopen-2019-033303

- Prepublication history and additional material for this paper are available online. To view these files, please visit the journal online (http://dx.doi org/10.1136/bmjopen-2019033303).

Received 30 July 2019 Revised 07 November 2019 Accepted 08 November 2019

Check for updates

(c) Author(s) (or their employer(s)) 2019. Re-use permitted under CC BY-NC. No commercial re-use. See rights and permissions. Published by BMJ.

For numbered affiliations see end of article.

Correspondence to Professor Sarah Hilmer; sarah.hilmer@sydney.edu.au

\section{ABSTRACT}

Objective To develop information leaflets for older inpatients and/or their carers to support deprescribing of antipsychotics, benzodiazepines/Z-drugs and proton pump inhibitors (PPIs).

Design An iterative mixed-methods approach involving face-to-face user testing and semi-structured interviews was performed over three rounds with consumers and hospital health professionals.

Setting Sydney, New South Wales, Australia.

Participants Thirty-seven consumers (or their carers) aged 65 years or older admitted to hospital in the previous 5 years and taking at least one regular medicine (not the medicine tested) completed user testing. Health professionals included a convenience sample of seven pharmacists and five doctors.

Methods The antipsychotic leaflet was tested in round 1 (consumers, $n=10$ ) and revised and retested in round 2 (consumers, $n=9$; health professionals, $n=5$ ). Findings from rounds 1 and 2 informed the design of the benzodiazepine/ Z-drug and PPI leaflets tested in round 3 (benzodiazepine/ Z-drug consumers, $n=9$; health professionals, $n=7$; PPI consumers, $n=9$ ). Findings from round 3 informed the final design of all leaflets. Consumer user testing involved 1213 questions to evaluate consumers' ability to locate and understand information in the leaflet. Usability by health professionals was assessed using the System Usability Scale (SUS).

Results At least $80 \%$ of consumers correctly found and understood the deprescribing information in the leaflets (9 of 12 information points in round 1 (antipsychotic); 10 of 12 in round 2; 12 of 13 (benzodiazepine/Z-drug) and 11 of 12 (PPI) in round 3). Consumers perceived the leaflets to be informative, well-designed and useful aids for ongoing medication management. The SUS scores obtained from health professionals were $91.0 \pm 3.8$ for the antipsychotic leaflet and $86.4 \pm 6.6$ for the benzodiazepine/Z-drug leaflet, indicating excellent usability.

Conclusions Understandable and easy-to-use consumer information leaflets were developed and tested by consumers and health professionals. The feasibility and utility of these leaflets to support deprescribing at transitions of care should be explored in clinical practice.
Strengths and limitations of this study

- This study was strongly informed by consumers including in the initial identification and prioritisation of the need for written consumer information on medicines deprescribed in hospital and the components of information content for its development.

- Consumer information leaflets were tested across multiple rounds with consumers (or their carers) aged over 65 years and multidisciplinary hospital health professionals.

- Further testing of consumer information leaflets in older hospital inpatients who have been deprescribed the medicine of interest is needed to inform further revisions, if required.

- This study did not explore the feasibility and effectiveness of consumer information leaflets to support deprescribing and reduce inappropriate medication use in older people.

\section{INTRODUCTION}

Polypharmacy and inappropriate medication use are highly prevalent in older people and may lead to adverse health outcomes including adverse drug events, falls, hospitalisations and mortality. ${ }^{1-3}$ Deprescribing, or the supervised withdrawal of inappropriate medications, ${ }^{4}$ may reduce inappropriate polypharmacy and its associated harm in older hospital inpatients. ${ }^{5}$ The process of deprescribing is often challenging and presents with several prescriber-related barriers (eg, prescribers' fear of negative consequences, poor insight into the appropriateness of their prescribing and low self-efficacy) ${ }^{6}$ and patient-related barriers (eg, fear of cessation, attachment to medications, and perceived lack of time and support from prescribers to deprescribe).$^{78}$ Resources to assist clinicians to deprescribe have resulted in the development of a number of drug classspecific deprescribing guidelines targeting 
benzodiazepines and Z-drugs, antipsychotics and proton pump inhibitors (PPIs). 910

Qualitative research into patient preferences for deprescribing has highlighted the importance of shared decision-making in enabling deprescribing, ${ }^{811}$ although time constraints can be a barrier to this process. ${ }^{12}$ How health professionals communicate with patients will depend on whether they are resistant to deprescribing, disinterested in their medicines overall or feel ambivalent towards deprescribing. ${ }^{8}$

Increasing attention on the importance of involving consumers and their carers in decision-making, and acknowledgement of their willingness to have their medicines deprescribed, ${ }^{13}$ has resulted in the development of consumer resources to support deprescribing. ${ }^{14} 15$ This includes deprescribing plans for PPIs developed by the Australian not-for-profit organisation responsible for supporting quality use of medicines, NPS MedicineWise, ${ }^{15}$ and the Eliminating Medications Through Patient Ownership of End Results (EMPOWER) brochures developed by the Canadian Deprescribing Network. ${ }^{14}$ EMPOWER brochures for sedatives and hypnotics, PPIs, sulfonylureas, antipsychotics, antihistamines and nonsteroidal anti-inflammatory drugs have been designed to empower older people to drive reductions in inappropriate prescribing. ${ }^{14}$ These brochures are intended as selfdirected education tools to encourage patients to initiate discussions about deprescribing with their physician. A systematic review of patient education material targeting deprescribing found fewer than half presented benefits and harms of deprescribing and most were suitable only for patients with above-average reading levels. ${ }^{16}$ Health literacy refers to the degree to which people are able to access, understand, appraise and apply health information in order to make decisions about their health. ${ }^{17}$ Low health literacy is associated with poorer interpretation of medication labels, increased risk of hospitalisation and mortality. ${ }^{18}$ Development of material suitable for older people who may have lower levels of health literacy and understanding of medicine information is crucial to enable shared deprescribing decision-making and improved health outcomes. ${ }^{19}$

Existing consumer resources to support deprescribing do not specifically target hospital inpatients and do not provide a personalised weaning plan. Although communication of changes made to medicines during hospital admission and particularly at transitions of care is critical to maintaining continuity of care, it is often inadequate. ${ }^{20}$ A cohort study of patients discharged from tertiary hospital in the USA identified only $22 \%$ of patients and/ or family members were involved in decisions made to their medicines during their hospital admission, despite $35 \%$ with plans to discontinue their regular medicines. ${ }^{21}$

Development of consumer information leaflets for older hospital inpatients to support deprescribing of the most common potentially inappropriate medications may assist in improving shared decision-making, self-management, and communication of medication changes initiated in hospital at transitions of care to patients, their families and their regular prescribers. Patient and public involvement in the coproduction of patient material is actively promoted and increasingly a necessity in health research. ${ }^{22}$ Despite this, involvement of consumers is variable, is often limited to written patient information within medicine packaging ${ }^{23}$ and is often not undertaken across all stages of research ${ }^{24}$ Furthermore, consumer or patient involvement is very rarely conducted at the onset of written material development. Involvement of consumers in the development of information leaflets is essential to ensure material is relevant, readable and understandable to the population of interest. Highly prevalent potentially inappropriate medications among older hospital inpatients include antipsychotics (up to $40 \%$ with dementia), ${ }^{25}{ }^{26}$ benzodiazepines (up to $30 \%)^{27-29}$ and PPIs (up to $40 \%$ ). ${ }^{27-29}$ The aim of this study was to develop consumer information leaflets for older hospital inpatients and their carers on the deprescribing of antipsychotics, benzodiazepines or Z-drugs and PPIs to support the deprescribing process during hospital admission and following hospital discharge.

\section{METHODS}

\section{Study design}

Three consumer information leaflets were developed and user tested with consumers and hospital health professionals via an iterative mixed-methods approach over three rounds.

\section{Participants}

Advertisements to recruit consumers and their carers were widely distributed across local health and media networks and research institutes in Sydney, Australia between May and August 2018. Face-to-face recruitment was also performed by researchers at local senior community and church events and in hospital waiting areas. Approximately 10 participants for each round of consumer user testing were sought, in line with existing user testing procedures to develop patient medication information. ${ }^{23}$ Consumers and their carers were reimbursed for their actual costs of travel and/or parking.

Consumers (and/or their carers) were eligible for inclusion in the study if they were aged 65 years and over, were admitted to hospital within the previous 5 years and took one or more regular medications. A carer was defined as a person who provides unpaid care and support to a family member or friend to manage their medications and/or medical condition. ${ }^{30}$ Consumers and their carers were excluded from participating in user testing of a leaflet if they self-reported prior or current use of the medicine of interest (antipsychotic, benzodiazepine/Z-drug or PPI). This is consistent with the recommendations for the development of consumer medicine information (CMI) ${ }^{23}$

Purposive and snowball sampling techniques were used to recruit hospital health professionals from general medicine and geriatric services, who may be more likely 
to practise deprescribing than those working in other services. This included recruitment through presentations at local hospital clinical meetings across two local health districts in Sydney, Australia. All hospital doctors and pharmacists were eligible to participate in user testing irrespective of level of experience. Recruitment continued until saturation of themes was reached and no further changes to the leaflets were identified.

\section{Initial design of leaflets}

All three consumer information leaflets are targeted towards hospital inpatients aged 65 years and over (and/ or their families/carers), for whom hospital clinicians have considered deprescribing of an antipsychotic, benzodiazepine/Z-drug and/or PPI. These leaflets were designed to be provided to patients and/or their families during their hospital admission and/or at discharge to aid in their understanding of medicine changes made during their hospital admission, and support shared decisionmaking of deprescribing decisions between patients, their families and health professionals. In addition, a personalised weaning plan, to be completed by a hospital clinician on hospital discharge, was included to support ongoing weaning of a medicine and communication with the patient's general practitioner. Although the leaflets were designed to be broad and encompass different indications of inappropriate use, the antipsychotic leaflet primarily targeted patients prescribed antipsychotics for behavioural and psychological symptoms of dementia.

The initial design and content of the two-page antipsychotic consumer information leaflet by the research team were based on available published literature, consumer resources and guidelines for the development of consumer information and the use of antipsychotics in older people. ${ }^{14} 1^{151-33}$ The research team had multidisciplinary clinical and research expertise in geriatric pharmacotherapy and research expertise in the development of patient-centred resources and shared decision-making. Development of the leaflets considered design features to accommodate age-related changes in vision (eg, increased font size), memory and cognition (eg, avoidance of medical jargon, use of short messages). ${ }^{34}$ Page 1 of the leaflet included general information on the use and deprescribing of the medicine (indication, common side effects, rationale for deprescribing, plan, withdrawal symptoms and monitoring, and non-drug options), as well as individualised information regarding the decision made during hospital admission or discharge about the use of the medicine (reduced dose, stopped or referral to general practitioner to review). Page 2 (reverse) contained a personalised initial 2-week weaning plan to be completed by the hospital pharmacist or doctor to assist patients and carers to follow their care plan. Separation of information from the personalised weaning plan over two pages was chosen to accommodate design principles for older people (eg, increased text size, white space), ${ }^{34}$ and provide display and storage options for the weaning plan for consumers (eg, display on the fridge at home). The Flesch-Kincaid Grade Level was calculated to assess the readability of the leaflets. ${ }^{35}$ Information in the leaflets was written below the recommended high school level (US eighth grade or lower). ${ }^{36}$

\section{Study procedure and analysis}

Three rounds of face-to-face consumer and health professional user testing and semi-structured interviews were performed by one of two research pharmacists experienced in qualitative research between May and August 2018 (SC and NJ). The antipsychotic leaflet was tested in rounds 1 and 2 (revised leaflet) and the benzodiazepine/ Z-drug and PPI leaflets in round 3 (figure 1).

\section{Consumer data collection}

Self-reported characteristics were recorded for consumers, including age, gender, level of education and health literacy. Health literacy was measured using a self-reported validated scale that comprised three questions. ${ }^{37} 38$

Consumer participants were provided with background information on the user testing process and were provided with one of three consumer leaflets to read prior to questioning. During the consumer interviews, the research pharmacist administered 12-13 user testing questions (UTQs) to evaluate the consumer's ability to locate and understand information, followed by semistructured interview questions to obtain broader feedback on design and content. UTQs were developed via consensus within the research team and related to key elements within the leaflet, including rationale and plan for deprescribing, withdrawal symptoms, monitoring and non-drug options (online supplementary file 1 table S1). Responses to UTQs were timed and recorded as 'found' if consumers were able to identify the correct location in the leaflet, 'found with difficulty' if located after two or more minutes and/or required two or more non-leading prompts (significant rewording of the question), and as 'understood' if their response aligned with the predetermined answers (online supplementary file 1 table S2). This user testing was based on the process previously performed in the design and user testing of $\mathrm{CMI}^{31}$ and medication labels. ${ }^{39}$

At the completion of the user testing, a semi-structured interview was performed with each participant to obtain broader feedback on the design and content of the leaflets (see interview guide in online supplementary file 2 ). Interviews were audio-recorded and transcribed externally by a professional transcription service.

\section{Consumer user testing analysis}

Response times for time to first location and understanding of information were described at the conclusion of each round. Questions found to create confusion with consumers in the first round of user testing were reworded for clarity for subsequent rounds. Following each round, responses to UTQs were compared with predetermined answers to identify information that was difficult to identify 


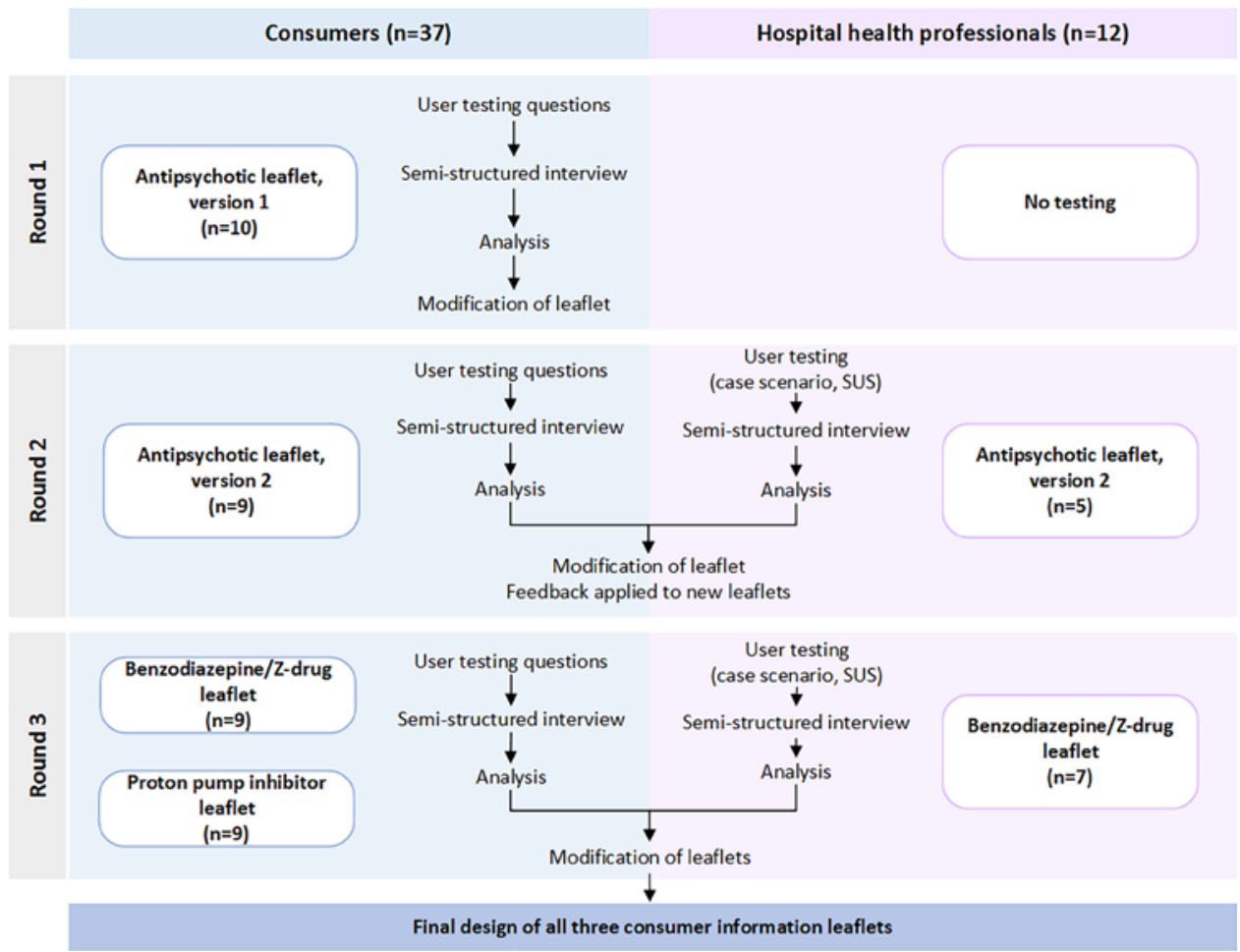

Figure 1 Redesign process with consumers and health professionals. SUS, System Usability Scale.

and/or understand, and required design and/or content changes prior to the next round. Coding of responses to UTQs was performed by one researcher and reviewed by members of the research team where responses did not clearly align with predetermined answers.

Responses to the three health literacy questions were coded using the 5-point Likert scale, where 1=always requiring assistance, difficulty learning all the time and no confidence completing medical forms, and $5=$ requiring no assistance, no difficulty learning and extremely confident completing medical forms. A score of 1-4 was categorised as having limited health literacy and score of 5 as adequate health literacy. ${ }^{40} 41$

\section{Hospital health professional data collection}

Profession, specialty and years of experience for each hospital health professional were recorded.

A research pharmacist provided participants with an example case scenario of an older hospital inpatient with a weaning plan for their antipsychotic or benzodiazepine/Z-drug. Participants were requested to complete the necessary patient and medicine details, including a 2-week weaning plan on the relevant draft leaflet. Time to complete both pages of the leaflet was recorded. This was then followed by completion of a selfadministered System Usability Scale (SUS) to assess their perceived usability of the leaflet. The SUS consists of 10 questions answered on a 5-point Likert scale to assess perceived usability of a product or tool. ${ }^{42}$ Although originally used for electronic-based tools, the SUS has since been used to assess the usability of paper-based tools. ${ }^{434}$
Questions were adapted from 'this system' to 'this leaflet' for relevance.

Feedback on the design, content and usability of the leaflets was obtained via one-on-one semi-structured interviews (see interview guide in online supplementary file 2). All interviews were audio-recorded and transcribed by a professional transcription service.

Hospital health professional user testing analysis

The mean scores for individually completed SUS questionnaires and time taken to complete both pages of the leaflet were summarised. SUS scores range between 0 and 100 , with scores above 70 considered to indicate good usability. ${ }^{45}$

\section{Semi-structured interview analysis}

Thematic analysis of consumer and health professional semi-structured interview transcripts to identify themes and subthemes was performed in NVivo V.11. Initial themes were identified using an inductive approach and subthemes further explored. These themes related to the content, design (layout, text, length) and usability of the information leaflets. Coding of themes and construction of matrices to summarise data were performed by one researcher and reviewed by members of the multidisciplinary research team for consensus.

\section{Redesign of leaflets}

The design of the leaflets was refined by the research team following feedback obtained from consumers and health professionals after each round. Collective changes were made to all leaflets following round 3 of user testing to 
ensure consistency in design and content across all leaflets. Final leaflets were produced by an external professional graphics design company.

Reporting of the results are in line with the Standards for Reporting Qualitative Research checklist. ${ }^{46}$

\section{Patient and public involvement}

Patient and public involvement in the coproduction of the consumer information leaflets occurred across several stages in this study. This included consumer representation in the initial identification and prioritisation of the need for written consumer information on medicines deprescribed in hospital, components of information content for its development and dissemination of the study. Patients and the public were not involved in data analysis or interpretation. Patient and public involvement in this study has been summarised in the Guidance for Reporting Involvement of Patients and the Public (GRIPP2) short form ${ }^{47}$ (see online supplementary file 3 table S1).

The research question and the development and testing of consumer information were informed by the priorities, experiences and preferences of consumer representatives on the steering committee for reducing inappropriate polypharmacy in older inpatients. Consumer representatives on the steering committee ensured consumer needs were considered throughout the study. Development of the consumer information leaflets was an iterative process, informed at each stage by consumer responses to UTQs and semi-structured interviews. Participants were recruited via consumer groups and networks.

The design of the study was based on the research team's multidisciplinary expertise in medicines information development and clinical studies with older people, as well as expertise and previous research on the development of usable CMI. Participants were not asked to assess the burden of the intervention and time required to participate in the research. The structure of interviews was based on consumer feedback in previous studies evaluating medicines information, and each participant selected their preferred time and location for the interview.

The final leaflets will be reviewed by consumer representatives on the steering committee. A lay report describing the results of the study will be disseminated through the consumer networks involved.

\section{RESULTS}

\section{Consumers}

Consumer characteristics are summarised in table 1 . Thirty-seven consumers, of whom eight were carers (who participated without the presence of the person they cared for), participated across three rounds of user testing. The majority of consumers were aged between 70 and 89 years, were female, born in Australia and spoke English as their main language at home. Approximately a quarter of consumers had perceived limited health literacy in one or more domains, reporting difficulty reading hospital or medicine information ( $\mathrm{n}=14,24 \%)$, difficulty learning about their medical or medicine information due to difficulty reading hospital or medicine information $(n=9$, $27 \%$ ), and lack of confidence completing medical forms $(\mathrm{n}=10,38 \%)$.

At least $80 \%$ of consumers located and understood the majority of information presented in the leaflet in each round (table 2). This included 9 of 12 information points found (including with difficulty) and understood in round 1,10 of 12 in round 2, and 12 of 13 (benzodiazepine/Zdrug leaflet) and 11 of 12 (PPI leaflet) in round 3. Of the consumers who located information, no more than two consumers required longer than 2 min or two or more prompts from the interviewer across all rounds. This included across two points of information tested in round 1 , two in round 2, seven in benzodiazepine/Z-drug and two in PPI user testing in round 3.

Questions that were found to be difficult for consumers to understand and required rewording are presented in online supplementary file 1 table S1. This primarily occurred following round 1 user testing and included questions related to the decision made about the medicine in hospital, reason for stopping, increasing side effects with age and what to do if they experience withdrawal symptoms. Following rewording of these UTQs, in addition to revision of wording and formatting of the presentation of this information (use of tick boxes, tables) in the leaflet in round 2, approximately $80 \%$ of consumers were able to locate and understand these four points of information, increasing to $90 \%-100 \%$ in round 3 .

All consumers correctly located and understood 10 of 13 information points in round 3 of testing the benzodiazepine/Z-drug leaflet and 10 of 12 information points in round 3 of testing the PPI leaflet. The only information points which were not found and understood in fewer than $90 \%$ of consumers in round 3 were the time over which benzodiazepines/Z-drugs are weaned (found and understood by $67 \%$ ) and side effects experienced while taking the PPI (found and understood by $78 \%$ ). The wording of the duration over which benzodiazepines/Zdrugs were weaned and order of appearance of side effects was subsequently changed following further questioning about these items during the semi-structured interviews.

Although the majority of consumers identified and understood what action to take if they experienced withdrawal symptoms, confusion remained over the difference between side effects, withdrawal symptoms and symptoms of the underlying condition returning. Greater emphasis using capitalisation of the words 'while taking' and 'coming off' in the headings and repositioning of this information in the leaflet were used to help distinguish between the timing of side effects and withdrawal symptoms. Although bolding and underlining of these words were suggested by consumers, capitalisation was chosen as this allowed for greater emphasis in the headings which were already bolded and presented in reverse type. These changes assisted in the identification of when 
Table 1 Summary of consumer characteristics $(n=37)$

\begin{tabular}{|c|c|c|c|c|}
\hline \multirow[b]{2}{*}{ Characteristics } & \multicolumn{2}{|c|}{ Antipsychotic } & \multirow{2}{*}{$\begin{array}{l}\text { Benzodiazepine/Z-drug } \\
\text { Round } 3 \\
(n=9)\end{array}$} & \multirow{2}{*}{$\begin{array}{l}\text { Proton pump inhibitor } \\
\text { Round } 3 \\
(\mathrm{n}=9)\end{array}$} \\
\hline & $\begin{array}{l}\text { Round } 1 \\
(n=10)\end{array}$ & $\begin{array}{l}\text { Round } 2 \\
(n=9)\end{array}$ & & \\
\hline \multicolumn{5}{|l|}{ Participant } \\
\hline Consumer & 8 & 9 & 6 & 6 \\
\hline Carer & 2 & 0 & 3 & 3 \\
\hline \multicolumn{5}{|l|}{ Age (years) } \\
\hline $50-59$ & 1 & 0 & 2 & 2 \\
\hline $60-69$ & 1 & 2 & 2 & 3 \\
\hline $70-79$ & 4 & 4 & 3 & 2 \\
\hline $80-89$ & 4 & 3 & 2 & 1 \\
\hline $90-99$ & 0 & 0 & 0 & 1 \\
\hline \multicolumn{5}{|l|}{ Gender } \\
\hline Male & 5 & 4 & 1 & 3 \\
\hline Female & 5 & 5 & 8 & 6 \\
\hline \multicolumn{5}{|l|}{ Country of birth } \\
\hline Australia & 6 & 8 & 7 & 8 \\
\hline Overseas & 4 & 1 & 2 & 1 \\
\hline \multicolumn{5}{|l|}{ Main language spoken at home } \\
\hline English & 10 & 9 & 9 & 8 \\
\hline Other & 0 & 0 & 0 & 1 \\
\hline \multicolumn{5}{|c|}{ Other languages spoken at home } \\
\hline None & 8 & 9 & 8 & 7 \\
\hline Other & 2 & 0 & 1 & 2 \\
\hline \multicolumn{5}{|l|}{ Highest level of education } \\
\hline University degree or higher & 5 & 2 & 3 & 3 \\
\hline Diploma & 1 & 4 & 1 & 3 \\
\hline Certificate & 1 & 1 & 1 & 0 \\
\hline Completed year 12 & 1 & 1 & 1 & 3 \\
\hline Completed year 10 & 1 & 1 & 3 & 0 \\
\hline Primary school & 1 & 0 & 0 & 0 \\
\hline \multicolumn{5}{|c|}{ Confidence completing medical forms } \\
\hline Extremely & 9 & 6 & 3 & 0 \\
\hline Quite & 1 & 1 & 5 & 5 \\
\hline Somewhat & 0 & 2 & 0 & 4 \\
\hline A little & 0 & 0 & 1 & 0 \\
\hline Not at all & 0 & 0 & 0 & 0 \\
\hline \multicolumn{5}{|c|}{$\begin{array}{l}\text { Requires assistance to read hospital/medicine } \\
\text { information }\end{array}$} \\
\hline None of the time & 9 & 7 & 6 & 6 \\
\hline A little of the time & 0 & 1 & 3 & 2 \\
\hline Some of the time & 1 & 1 & 0 & 1 \\
\hline Most of the time & 0 & 0 & 0 & 0 \\
\hline All of the time & 0 & 0 & 0 & 0 \\
\hline
\end{tabular}




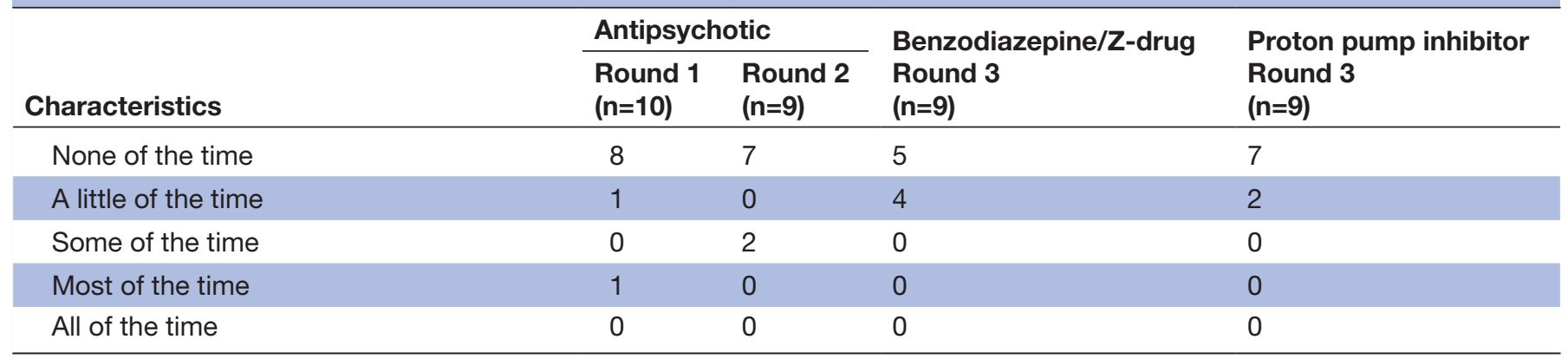

symptoms would likely occur; however, explanation of the underlying difference between withdrawal symptoms, side effects and the symptoms of the underlying condition returning remained challenging across rounds:

Well, you go back to the feeling, that you had before you started taking the medication. And that's what I never want to do. (Benzodiazepine R3, P9)

Withdrawal symptoms...to me means certain side effects once the medicines have been ceased. (Antipsychotics R2, P3)

A summary of consumer perceptions is presented in table 3 . The user testing process was found to be challenging for consumers who revealed feeling overwhelmed due to unfamiliarity with the medicine tested and no opportunity to read the leaflet at home multiple times prior to the user testing process. Overall, the majority of consumers found the leaflets to be informative and well designed, and perceived the leaflets to be useful aids to assist with their understanding and ongoing plan for their medicines following discharge from hospital:

It's altogether positive. It's letting you understand the treatment that's been given to you - the why - there's a little bit of how it works, there's the possible side effects. Then in this case, how do you stop it? So, there's understanding and control, and I think it empowers the patient if they're willing. But if it's not empowering the patient, at least it's empowering the carer.

(Benzodiazepine R3, P8)

\section{Hospital health professionals}

Twelve hospital health professionals, comprising seven pharmacists and five doctors, participated in user testing (table 4). The majority of participants were female and had practised for between 1 and 10 years.

Participants took an average of 3:44 min (range: 2:076:20 min) (pharmacists: 4:22 min, doctors: $2: 55 \mathrm{~min}$ ) to complete both pages of the consumer leaflet. A summary of SUS scores for each question is presented in figure 2. The average \pm SD SUS score for use of the antipsychotic leaflet was $91.0 \pm 3.8$ and $86.4 \pm 6.6$ for the benzodiazepine/ Z-drug leaflet, indicating excellent usability. ${ }^{45}$

A summary of health professional perceptions is presented in table 5. Overall, health professionals found the leaflets easy to understand, clear and useful for patients and themselves as education aids. All participants agreed or strongly agreed that the leaflets were easy to use, components within the leaflet were well integrated, and that they would feel very confident to use the leaflet in practice and use it frequently. Participants found the leaflets would be particularly beneficial for carers who often manage medicines:

I think it's good to give something to the patient or carer because just telling them we're stopping it is not enough. And also what I find is that sometimes when pharmacists see the patient on the ward - they are usually the patients who are not going to be caring for their medicines. So if you can have something in writing that can be passed on to the carer, it would help a lot. (Antipsychotics R2, P2-Pharmacist)

I just wonder if someone with cognitive impairment and dementia is going to benefit from reading that - probably not. But most of the patients we see probably wouldn't read it. So it could be given to the carer as well in this scenario. (Benzodiazepines R3, P6Junior Medical Officer)

As was the case in consumer interviews, suggested improvements to the leaflets included use of colour and reduced content; however, there was uncertainty as to which or whether any content could be removed:

There are a lot of words but I can't think of anything that you would remove to make it less cluttered. It's not that cluttered to begin with. (Antipsychotics R2, P7-Junior Medical Officer)

Health professionals differed in perceptions on who is likely to complete the leaflet in clinical practice (ie, pharmacist or junior doctor) and perceived that time and resources (eg, adequate staffing to perform additional tasks) to be potential barriers to providing counselling and completing the leaflet:

Ideally, I'd like to use it as a counselling aid, but I think practically, I'd be strapped for time and would end up just handing it to them with the discharge summary paperwork. (Antipsychotics R2, P7-Junior Medical Officer)

I believe pharmacists would probably be better in 
Table 2 Summary of quantitative findings from consumer user testing

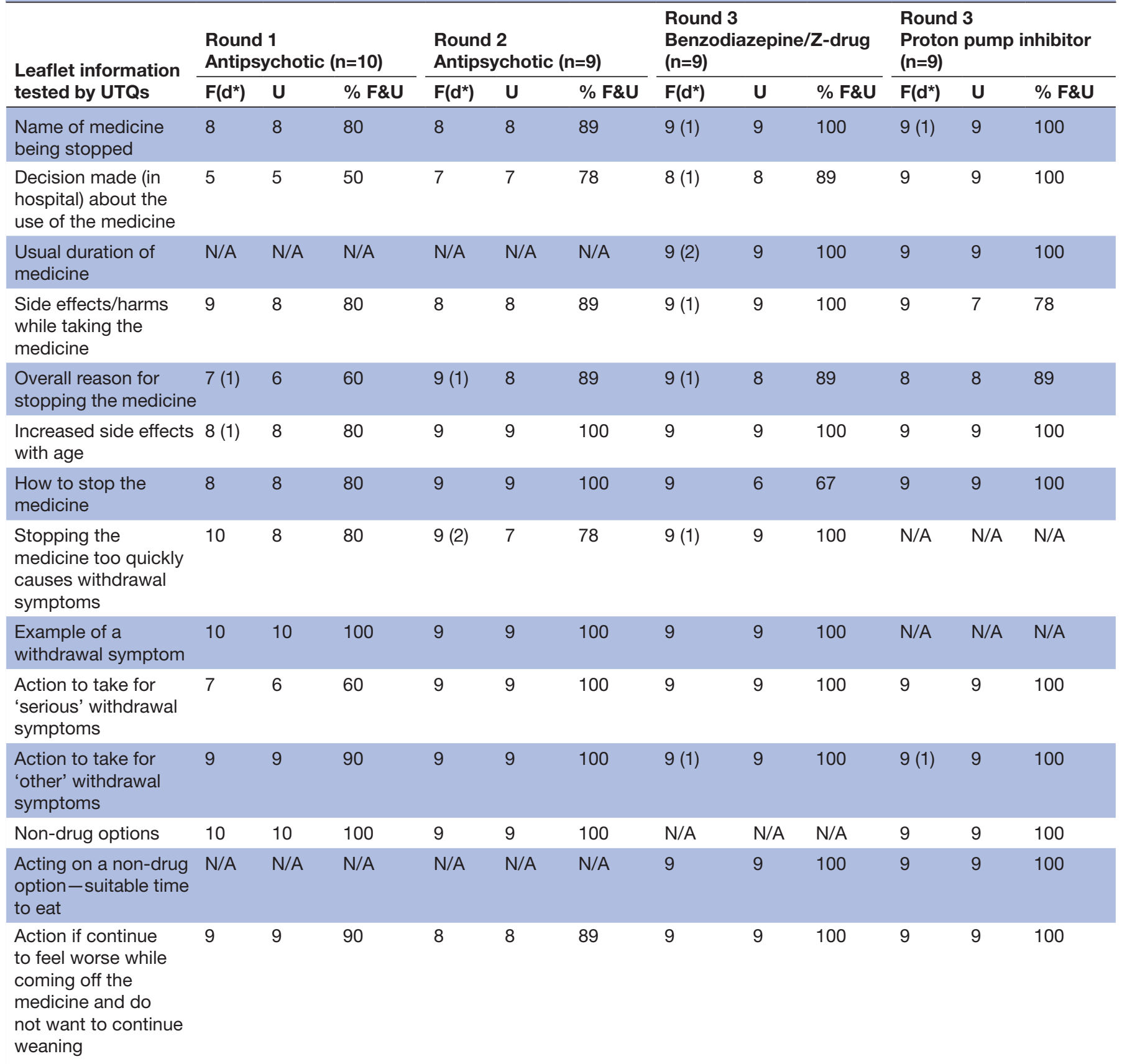

See online supplementary file 1 table $\mathrm{S} 1$ for UTQs asked in each round of user testing.

$\mathrm{d}^{*}$, number of participants who found the answer with difficulty ( $\geq 2 \mathrm{~min}$ and/or $\geq 2$ prompts); F, found;N/A, information on the leaflet which was not tested by UTQ; U, understood;UTQ, user testing question.

completing it, especially because they check the discharge summary and sometimes they put in the dates and change the format and things. So if they can do this, I think they will be, yeah, a bit more meticulous and better. (Benzodiazepines R3, P11-Registrar)

\section{Redesign of leaflets}

Changes made to the content and design of leaflets following each round of feedback from consumer and health professionals are summarised in online supplementary file 1 table S3. The majority of changes were made in the first round of consumer testing and included increases in font size, spacing, reduction in content, and clarity in wording and presentation of information. Final designs of all three leaflets were produced as editable PDFs to enable completion by a hospital doctor or pharmacist electronically if preferred (online supplementary file 4). Readability of each leaflet, as assessed by the FleschKincaid Grade Level, increased in subsequent rounds and remained below the recommended eighth-grade level 


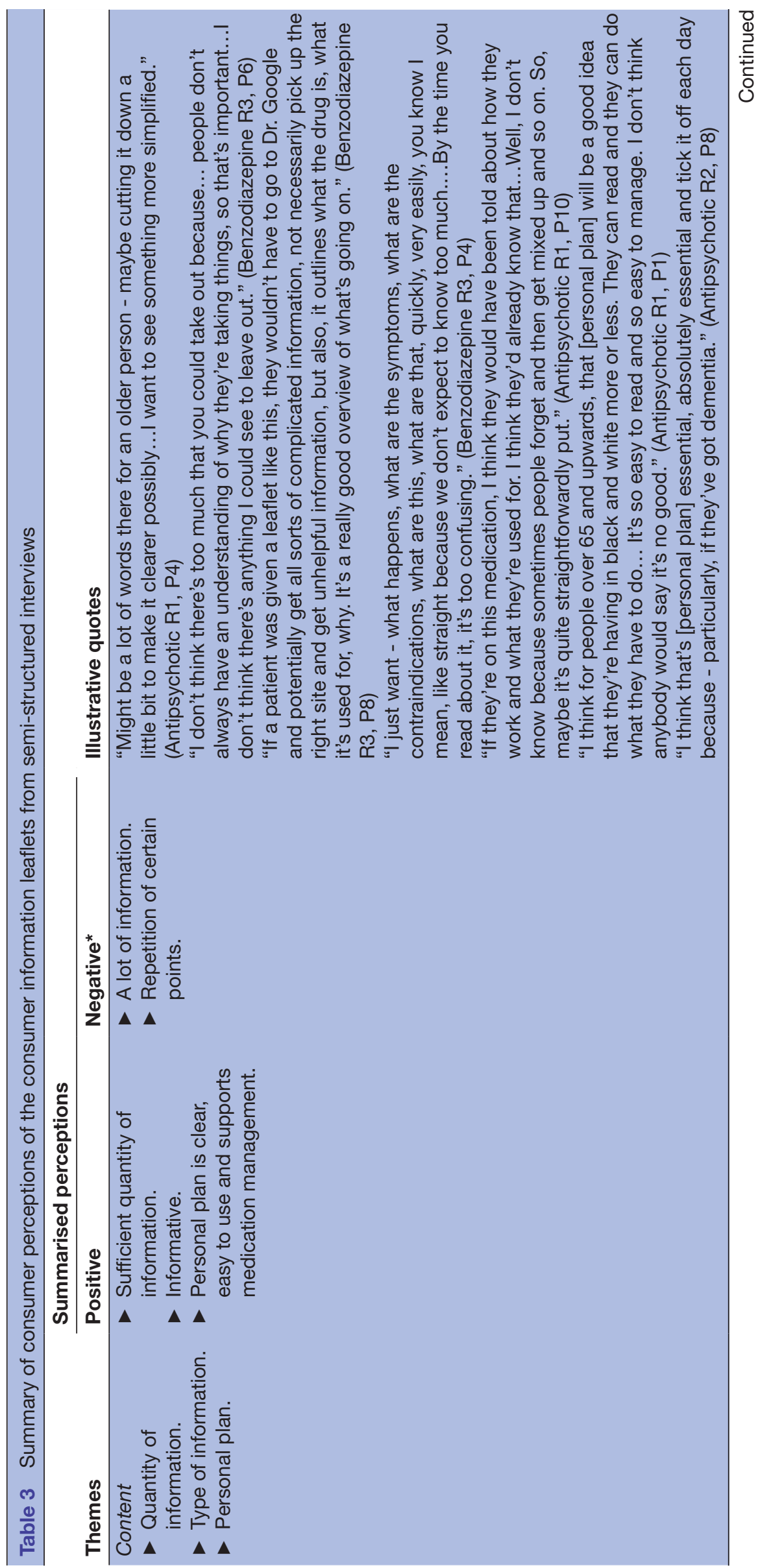




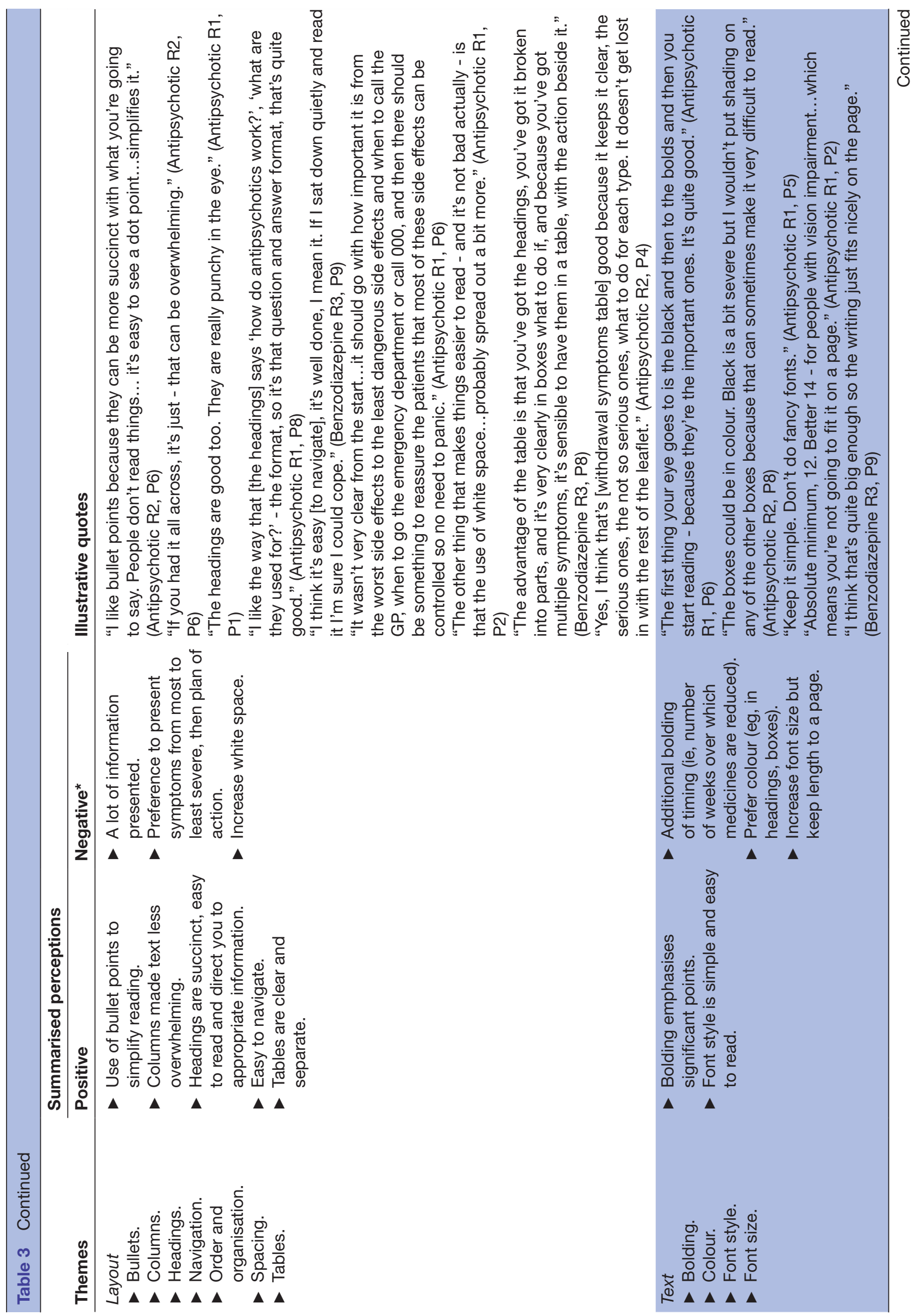




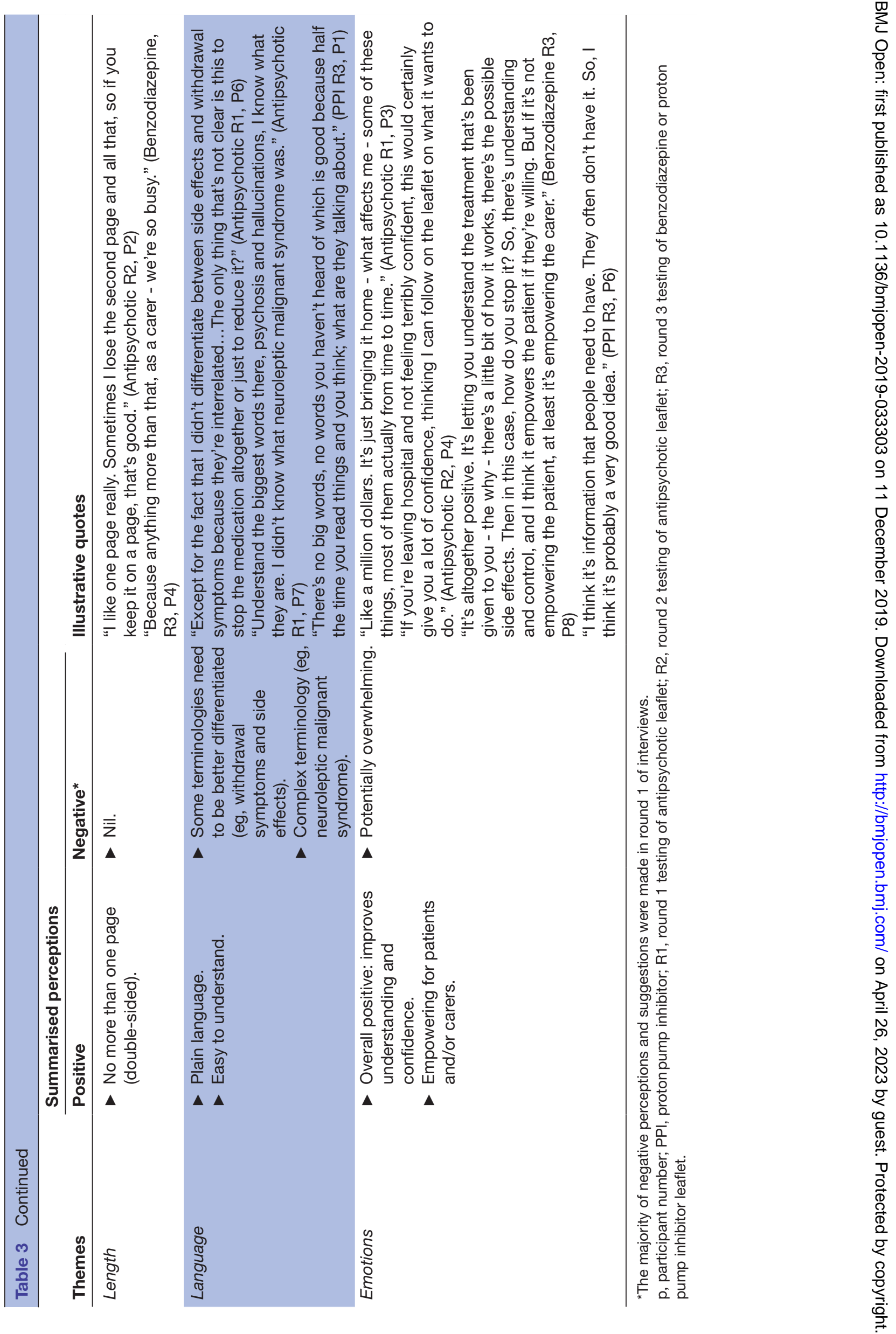


Table 4 Summary of health professional characteristics

Health professionals

Characteristics $(n=12)$

$\begin{array}{ll}\text { Gender } & \\ \text { Male } & 4 \\ \text { Female } & 8\end{array}$

\begin{tabular}{|c|c|}
\hline \multicolumn{2}{|l|}{ Age (years) } \\
\hline $18-29$ & 4 \\
\hline $30-39$ & 6 \\
\hline $40-49$ & 1 \\
\hline $50-59$ & 1 \\
\hline \multicolumn{2}{|l|}{ Profession } \\
\hline Pharmacist & 7 \\
\hline Junior doctor & 4 \\
\hline Registrar & 1 \\
\hline \multicolumn{2}{|c|}{ Length of time as practitioner (years) } \\
\hline$<1$ & 1 \\
\hline $1-5$ & 4 \\
\hline $6-10$ & 4 \\
\hline$>10$ & 3 \\
\hline \multicolumn{2}{|l|}{ Area of specialty } \\
\hline General & 7 \\
\hline Geriatrics & 3 \\
\hline Other & 2 \\
\hline
\end{tabular}

Time in specialty (years)

\begin{tabular}{ll}
$<1$ & 3 \\
$1-5$ & 4 \\
$6-10$ & 4 \\
$>10$ & 1 \\
\hline
\end{tabular}

(antipsychotic: from 9.1 to 6.9 ; benzodiazepine/Z-drug: from 6.4 to 6.1 ; PPI: from 6.1 to 6.0$)$.

\section{DISCUSSION}

This is the first study to report consumer and health professional user testing of consumer information leaflets for deprescribing in people over the age of 65 years. Patient and public involvement across several stages of this study ensured consumer needs were considered in the development of consumer-friendly leaflets. Over $80 \%$ of consumers correctly found and understood the majority of information in the leaflets and perceived the leaflets to be informative, well designed and a valuable resource to assist with deprescribing following hospital discharge. The leaflets were perceived to have excellent usability by hospital health professionals and perceived as likely to be completed by pharmacists and/or junior doctors depending on time and resources available.
Previous Australian studies of development and user testing of CMI and medicine labels have been performed in consumers younger than 70 years. ${ }^{48}{ }^{49}$ In line with Farage $e t a l l^{34}$ challenges in designing and user testing of medication information in an older cohort were due to age-related decline in memory and cognition, including difficulty learning and retaining new information, interpreting written and verbal information, and reduced processing speed. Although self-reported health literacy was high among consumer participants, several challenges were found during the user testing process. Consumers reported feeling overwhelmed during questioning and that they would benefit from the opportunity to read the leaflet multiple times at home prior to user testing, which could occur in practice but is not part of standard user testing methodology. Particularly challenging terminology and design included the 'decision made to stop the medicine', which was not found and understood by $50 \%$ of consumers in round 1, despite being among the first piece of information presented in the leaflet. In addition to a change in wording for subsequent rounds, design modifications including the use of check boxes (ie, reduced, stopped, refer to general practitioner) and increased spacing were necessary to improve consumers' understanding of this component of the leaflet. This highlights the complexity in designing medicine information in this population and the need for consideration of design elements (eg, larger font size, spacing, bolding) in addition to content. Difficulty understanding the underlying differences between withdrawal symptoms and side effects was also evident across rounds, suggesting the need for additional verbal counselling from a health professional in clinical practice and/or use of visual aids. ${ }^{50}$

Hospital health professionals were positive overall about the design, content and perceived benefit of the leaflets in practice. Suggested design and content changes largely aligned with consumer perceptions and suggestions. Existing consumer information leaflets or brochures targeting deprescribing of potentially inappropriate medications comprise generalised weaning plans. ${ }^{1415} \mathrm{~A}$ unique feature of the leaflets designed in this study is the personalised weaning plan for the initial 2 weeks following hospital discharge, to be completed for each patient by a health professional. The inclusion of this personal plan was perceived positively by both health professionals and consumers, and particularly beneficial for medications with longer and more complex weaning plans, such as those seen with benzodiazepines and antipsychotics. ${ }^{10}$

Existing consumer resources for deprescribing of inappropriate medications, including the EMPOWER brochures ${ }^{14}$ and NPS PPI leaflet, ${ }^{15}$ provide general guidance for weaning medicines and alternative management, with the intention for older people to seek a health professional to discuss a plan to discontinue their medicines. Use of the EMPOWER brochures has been explored in the community and hospital setting to reduce 
I think that I would like to use this leaflet frequently

I found the leaflet unnecessarily complex

I thought the leaflet was easy to use

I think that I would need the support of a technical person to be able to use this leaflet

I found the various functions in this leaflet were well integrated

I thought there was too much inconsistency in this leaflet

I would imagine that most people would learn to use this leaflet quickly

I found the leaflet very cumbersome to use

I felt very confident using the leaflet

I needed to learn a lot of things before I could get going with this leaflet

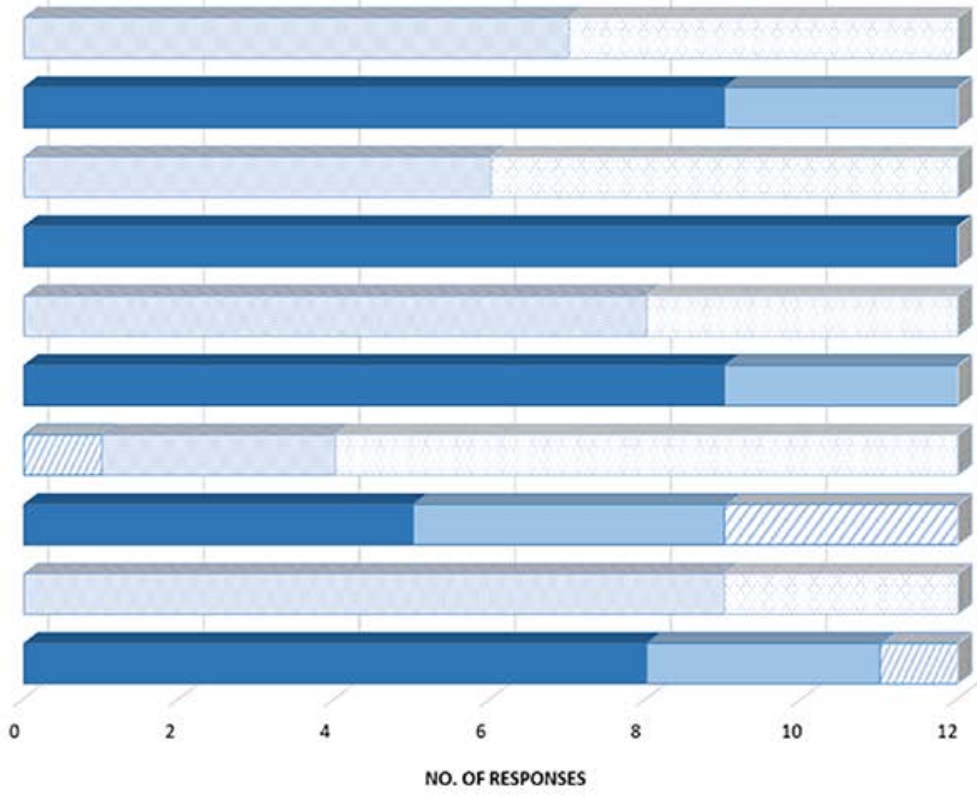

EStrongly disagree $\square$ Disagree $\square$ Neutral $\square$ Agree $\square$ Strongly agree

Figure 2 System Usability Scale responses from health professionals for antipsychotic and benzodiazepine consumer information leaflets.

inappropriate use of benzodiazepines and Z-drugs in older adults aged 65 years and over. ${ }^{51} 52$ In contrast, the consumer leaflets developed in this study were designed to be provided to older hospital inpatients at the time a decision has been made by a clinician to start the deprescribing process.

Involvement of consumers in primary care research is variable and most frequently involves representation in steering committees and dissemination of research findings. ${ }^{24}$ Although participation of consumers in user testing of information leaflets appears to be increasing, ${ }^{5354}$ these are primarily focused on CMIs and are currently only mandatory in Europe. ${ }^{23}$ Coproduction of information leaflets across all stages of the research process is uncommon and has not yet been performed for leaflets specific to deprescribing. In Australia, previous research into alternative formats of CMI has described the involvement of consumers across multiple stages of research. ${ }^{31}$ This included consumer and health professional participation in an initial needs analysis to investigate perceptions of CMI and to inform the development of alternative CMI formats. Evaluation of these leaflets was undertaken via a user testing process. ${ }^{31}$ The method from this report was used to inform the design of this study and to increase involvement of consumers in the development of consumer information leaflets.

This study had a number of strengths and limitations. A significant strength of this study is the high level of consumer engagement from initial development of the research question to testing of the consumer information leaflets to ensure their readability and understandability. The leaflets were tested across multiple rounds with input from consumers and multidisciplinary hospital health professionals. This included contribution from carers who are likely to provide medical care and/or support medication management for older people, particularly for those living with dementia. Although the same leaflet was not tested across all three rounds with 10 participants, which is typical in user testing, ${ }^{23}$ the design and content were largely consistent across all leaflets, with the exception of medicine-specific information including indication, side effects and withdrawal symptoms. This method also provided the opportunity to test the content of three different medication leaflets. Efforts were made to ensure wording was consistent between the three leaflets where possible. Design and content changes reflected feedback from participants and overall recommendations for the design of material for older people. ${ }^{34}$ Patient and public involvement did not occur at data analysis and interpretation stages. Inclusion of consumer representatives at these stages could provide further patient perspectives and identify themes missed or misinterpreted by researchers.

The leaflets were not tested with consumers who had previously taken the medicine, thereby reducing potential bias from existing medicine knowledge. ${ }^{23}$ Previous profession of consumers was not recorded and therefore consumers with prior healthcare backgrounds may have been included. Participants may not be representative of all older patients in whom deprescribing decisions are made in hospital. For example, approximately three-quarters of consumers in this study had perceived adequate health literacy in one or more domains, compared with findings from the 2018 Australian Health Literacy Survey which identified $39 \%$ of people over 65 years found it always easy to understand health information well enough to know what to do. ${ }^{19}$ The leaflets were not retested following incorporation of all findings after round 3. Further testing in the population of 


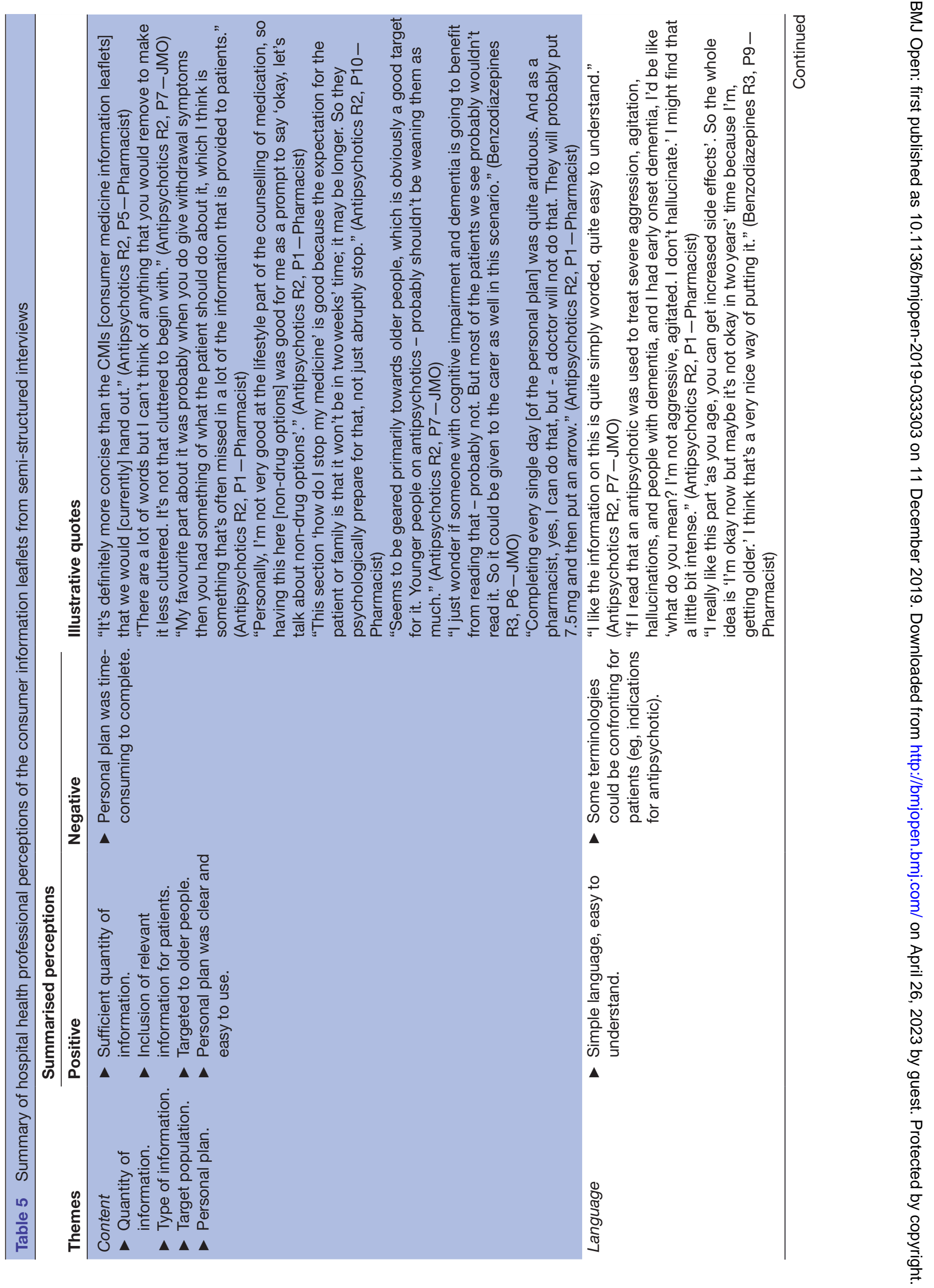




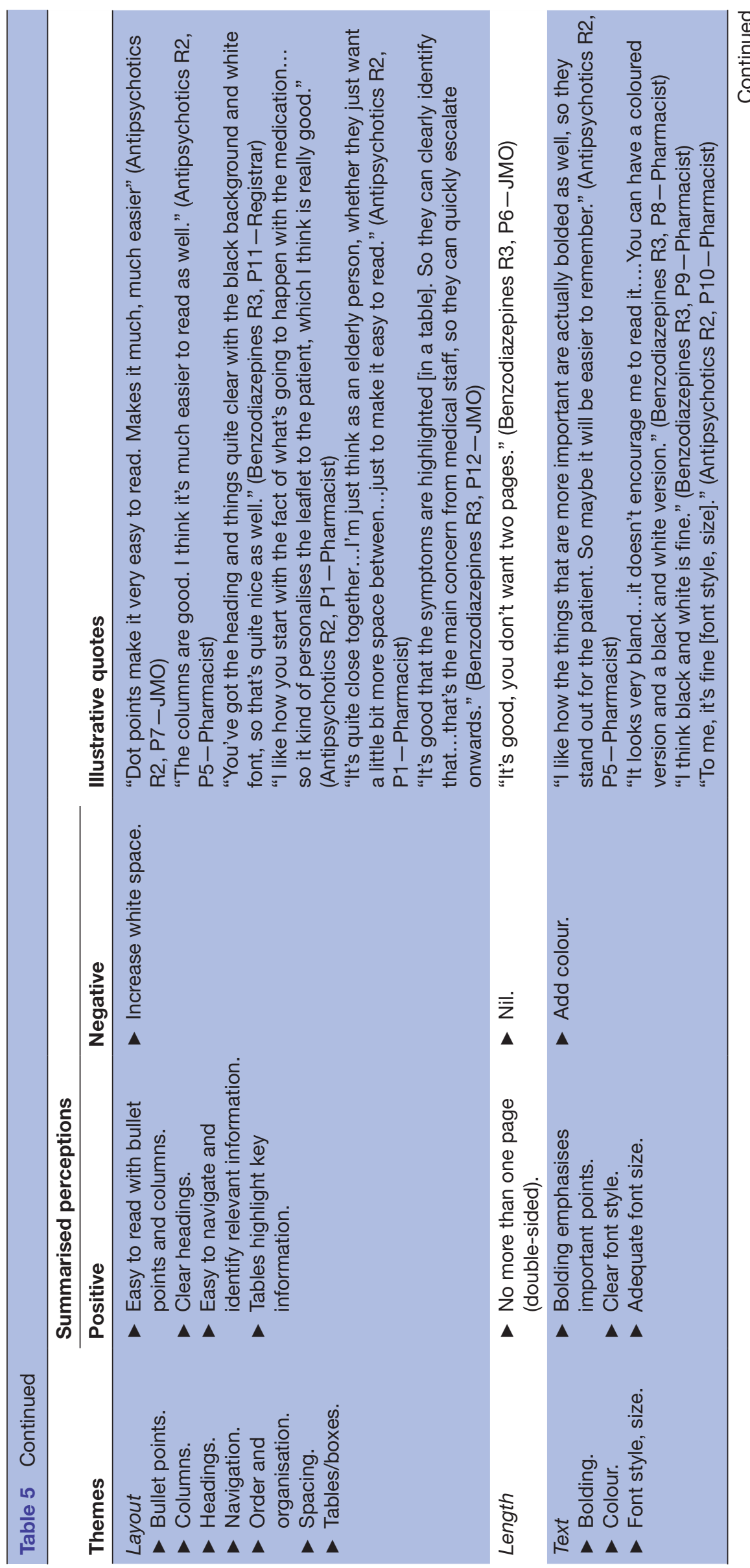




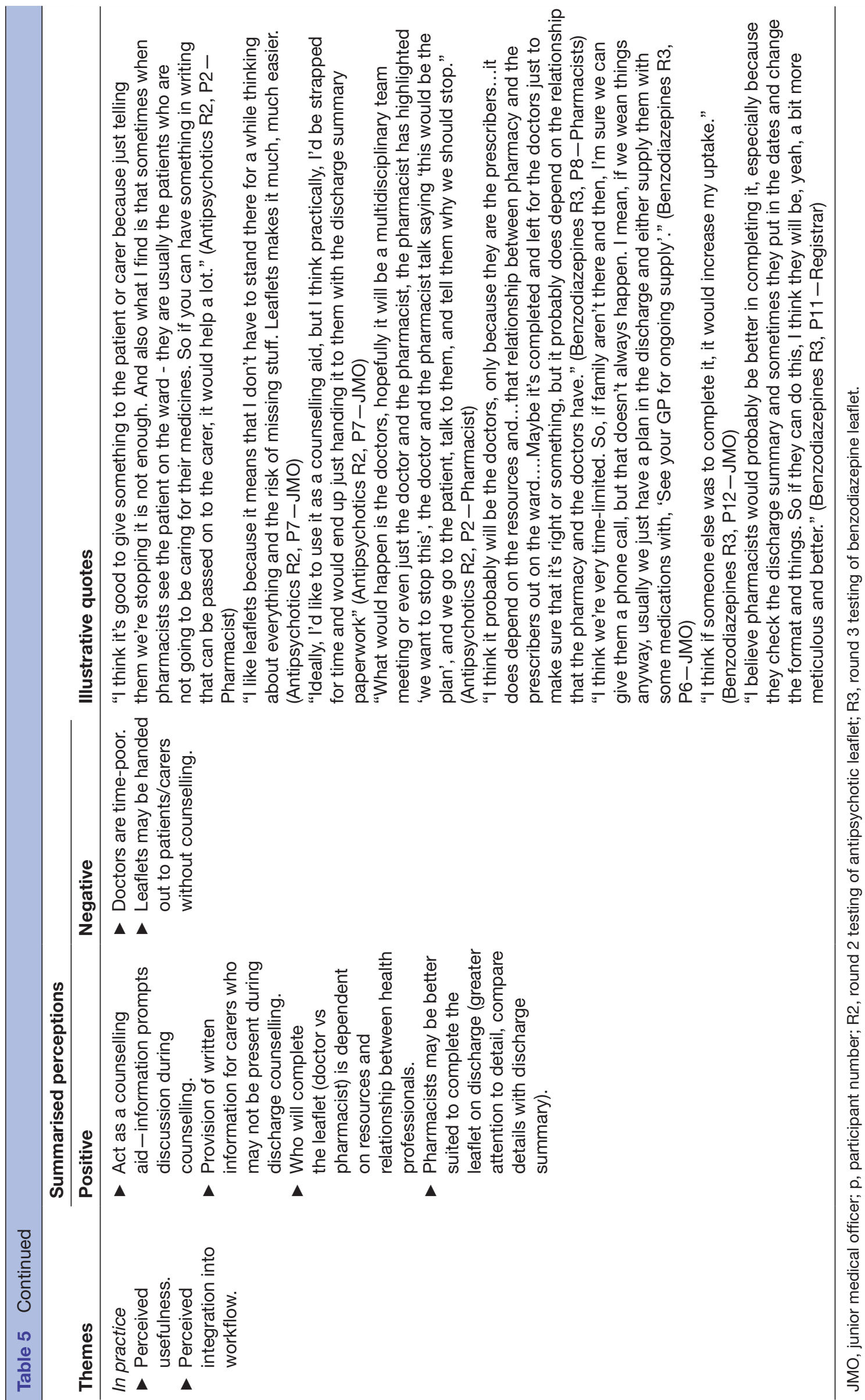


interest (older hospital inpatients who have the medicine of interest deprescribed) is needed to inform additional revisions of the leaflets, if required. Previous studies have performed user testing in older people up to the age of 70 years, ${ }^{48}{ }^{49}$ whereas consumers in this study were primarily aged over 70. Difficulties encountered undertaking the user testing process in this study suggest that further consideration of a person's degree of independence and ability to self-manage their medications may be necessary. The use of colour was frequently suggested by consumers and health professionals; however, the leaflets were designed in black and white as there is likely to be limited availability of colour printing in hospitals. Researchers considering the development of consumer information leaflets for additional medicines should ensure user testing with consumers is performed to develop specific design and content features understandable by the population of interest. The feasibility and effectiveness of the consumer leaflets to support deprescribing and reduce inappropriate medication use in older hospital inpatients were not explored in this study and should be considered in future studies.

\section{CONCLUSION}

Three consumer information leaflets to support deprescribing for older inpatients have been developed and tested by consumers and health professionals. Patient and public involvement in this study ensured the needs of consumers were considered across different stages in the research process. Future studies should also consider consumer involvement in the analysis and interpretation of user testing results and interview transcripts to provide additional patient perspectives. Further testing in clinical practice may inform additional modifications. The feasibility and effectiveness of the leaflets to support deprescribing at transitions of care should be explored in clinical practice.

\section{Author affiliations}

${ }^{1}$ Departments of Clinical Pharmacology and Aged Care, Kolling Institute of Medical Research, Royal North Shore Hospital, St Leonards, New South Wales, Australia ${ }^{2}$ Northern Clinical School, The University of Sydney Faculty of Medicine and Health, Sydney, New South Wales, Australia

${ }^{3}$ Sydney Pharmacy School, The University of Sydney Faculty of Medicine and Health, Sydney, New South Wales, Australia

${ }^{4}$ Charles Perkins Centre, The University of Sydney, Sydney, New South Wales, Australia

${ }^{5}$ School of Public Health, The University of Sydney Faculty of Medicine and Health,

Sydney, New South Wales, Australia

${ }^{6}$ Centre for Education and Research on Ageing, Concord Hospital, Sydney, New South Wales, Australia

${ }^{7}$ Concord Clinical School, The University of Sydney Faculty of Medicine and Health, Sydney, New South Wales, Australia

Acknowledgements The authors wish to thank health and consumer groups and networks including Sydney and Northern Sydney Local Health Districts, Dementia Australia, COTA Australia, Northern Sydney Primary Health Network, Northern Sydney Carer Support Service and local community support groups for assisting with recruitment. The authors also gratefully thank all participants for their contribution to the design and user testing of the consumer information leaflets, and all members of the NSW Health Translational Research Grant 274 Reducing Inappropriate Polypharmacy research group.

Contributors All authors contributed to the study concept and design. NJ, SC, MD, $\mathrm{PA}$ and $\mathrm{SH}$ developed the consumer information leaflets. $\mathrm{NJ}$ and $\mathrm{SC}$ conducted the interviews and data analysis. All authors contributed to interpretation of the data. $\mathrm{NJ}$ and SC drafted the manuscript. All authors critically revised the manuscript for important intellectual content and approved the final manuscript. The corresponding author attests that all listed authors meet the authorship criteria and that no others meeting the criteria have been omitted.

Funding The work was supported through the Australian Government Medical Research Future Fund (MRFF) Rapid Applied Research Translation Program grant awarded to Sydney Health Partners. The funding body had no role in the study design; collection, analysis and interpretation of data; or the preparation, review or approval of the manuscript. $\mathrm{JJ}$ is supported by a National Health and Medical Research (NHMRC) Career Development Fellowship unrelated to the submitted work.

Competing interests None declared.

Patient consent for publication Not required.

Ethics approval This study was approved by the Northern Sydney Local Health District Human Research Ethics Committee (HREC/17/HAWKE/138). Written informed consent was obtained from all participants prior to participation.

Provenance and peer review Not commissioned; externally peer reviewed.

Data availability statement All data relevant to the study are included in the article or uploaded as supplementary information.

Open access This is an open access article distributed in accordance with the Creative Commons Attribution Non Commercial (CC BY-NC 4.0) license, which permits others to distribute, remix, adapt, build upon this work non-commercially, and license their derivative works on different terms, provided the original work is properly cited, appropriate credit is given, any changes made indicated, and the use is non-commercial. See: http://creativecommons.org/licenses/by-nc/4.0/.

ORCID iD

Natali Jokanovic http://orcid.org/0000-0003-1830-9930

\section{REFERENCES}

1 van der Stelt CAK, Vermeulen Windsant-van den Tweel AMA, Egberts ACG, et al. The association between potentially inappropriate prescribing and medication-related hospital admissions in older patients: a nested case control study. Drug Saf 2016;39:79-87.

2 Ní Chróinín D, Neto HM, Xiao D, et al. Potentially inappropriate medications (PIMs) in older hospital in-patients: prevalence, contribution to hospital admission and documentation of rationale for continuation. Australas J Ageing 2016;35:262-5.

3 Wastesson JW, Morin L, Tan ECK, et al. An update on the clinical consequences of polypharmacy in older adults: a narrative review. Expert Opin Drug Saf 2018;17:1185-96.

4 Reeve E, Gnjidic D, Long J, et al. A systematic review of the emerging definition of 'deprescribing' with network analysis: implications for future research and clinical practice. $\mathrm{Br} J \mathrm{Clin}$ Pharmacol 2015;80:1254-68.

5 Thillainadesan J, Gnjidic D, Green S, et al. Impact of deprescribing interventions in older hospitalised patients on prescribing and clinical outcomes: a systematic review of randomised trials. Drugs Aging 2018;35:303-19.

6 Anderson K, Stowasser D, Freeman C, et al. Prescriber barriers and enablers to minimising potentially inappropriate medications in adults: a systematic review and thematic synthesis. BMJ Open 2014;4:e006544.

7 Reeve E, To J, Hendrix I, et al. Patient barriers to and enablers of deprescribing: a systematic review. Drugs Aging 2013;30:793-807.

8 Weir K, Nickel B, Naganathan V, et al. Decision-Making preferences and deprescribing: perspectives of older adults and companions about their medicines. J Gerontol B Psychol Sci Soc Sci 2018;73:e98-107.

9 Primary Health Tasmania. Deprescribing guides, 2018. Available: https://www.primaryhealthtas.com.au/resources/deprescribingguides/ [Accessed 07 Dec 2018].

10 Canadian Deprescribing Network. Deprescribing guidelines and algorithms, 2018. Available: https://deprescribing.org/resources/ deprescribing-guidelines-algorithms/ [Accessed 07 Dec 2018]. 
11 Reeve E, Low L-F, Hilmer SN. Beliefs and attitudes of older adults and carers about deprescribing of medications: a qualitative focus group study. Br J Gen Pract 2016;66:e552-60.

12 Pieterse AH, Stiggelbout AM, Montori VM. Shared decision making and the importance of time. JAMA 2019;322.

13 Reeve E, Wiese MD, Hendrix I, et al. People's attitudes, beliefs, and experiences regarding polypharmacy and willingness to deprescribe. J Am Geriatr Soc 2013;61:1508-14.

14 Canadian Deprescribing Network. Empower brochures, 2014. Available: https://deprescribing.org/resources/deprescribinginformation-pamphlets/ [Accessed 04 Dec 2018].

15 NPS MedicineWise. PPI therapy for managing GORD, 2018 Available: https://cdn0.scrvt.com/08ab3606b0b7a8ea53fd0b40 b1c44f86/50240b737233cd47/a615f8d13d0c/NPS1993_SSDSM_ PAP v5.1.pdf [Accessed 07 Dec 2018].

16 Fajardo MA, Weir KR, Bonner C, et al. Availability and readability of patient education materials for deprescribing: an environmental scan. Br J Clin Pharmacol 2019;85:1396-406.

17 Sørensen K, Van den Broucke S, Fullam J, et al. Health literacy and public health: a systematic review and integration of definitions and models. BMC Public Health 2012;12:80.

18 Berkman ND, Sheridan SL, Donahue KE, et al. Low health literacy and health outcomes: an updated systematic review. Ann Intern Med 2011;155:97-107.

19 Australian Bureau of Statistics. Health literacy survey 2018. Canberra, Australia; 2018

20 Vermeir P, Vandijck D, Degroote S, et al. Communication in healthcare: a narrative review of the literature and practical recommendations. Int J Clin Pract 2015;69:1257-67.

21 Kadoyama KL, Noble BN, Izumi S, et al. Frequency and documentation of medication decisions on discharge from the hospital to hospice care. J Am Geriatr Soc 2019;67:1258-62.

22 Greenhalgh T, Hinton L, Finlay T, et al. Frameworks for supporting patient and public involvement in research: systematic review and co-design pilot. Health Expect 2019;22:785-801.

23 Raynor DK. User testing in developing patient medication information in Europe. Research in Social and Administrative Pharmacy 2013;9:640-5.

24 Blackburn S, McLachlan S, Jowett S, et al. The extent, quality and impact of patient and public involvement in primary care research: a mixed methods study. Res Involv Engagem 2018;4.

25 Gallagher P, Curtin D, de Siún A, et al. Antipsychotic prescription amongst hospitalized patients with dementia. QJM 2016;109:589-93

26 Rios S, Perlman CM, Costa A, et al. Antipsychotics and dementia in Canada: a retrospective cross-sectional study of four health sectors. BMC Geriatr 2017;17:244.

27 Zhang X, Zhou S, Pan K, et al. Potentially inappropriate medications in hospitalized older patients: a cross-sectional study using the beers 2015 criteria versus the 2012 criteria. Clin Interv Aging 2017:12:1697-703.

28 Manias E, Maier A, Krishnamurthy G. Inappropriate medication use in hospitalised oldest old patients across transitions of care. Aging Clin Exp Res 2019;31:1661-73.

29 Bo M, Gibello M, Brunetti E, et al. Prevalence and predictors of inappropriate prescribing according to the Screening Tool of Older People's Prescriptions and Screening Tool to Alert to Right Treatment version 2 criteria in older patients discharged from geriatric and internal medicine ward. Geriatr Gerontol Int 2019;19:5-11.

30 Carers Australia. About carers, 2019. Available: https://www. carersaustralia.com.au/about-carers/ [Accessed 01 Apr 2019].

31 Aslani P, Hamrosi K, Feletto E, et al. Investigating consumer medicine information (I-CMI) project. Sydney: The Pharmacy Guild of Australia and Australian Government Department of Health and Ageing, 2010.

32 Raynor DK, Dickinson D. Key principles to guide development of consumer medicine Information-Content analysis of information design Texts. Ann Pharmacother 2009;43:700-6.
33 NSW Health Translational Research Grant Scheme project group. References for consumer information leaflets, 2018. Available: http:// www.nswtag.org.au/wp-content/uploads/2018/06/References-forconsumer-information-leaflets-TAG.pdf [Accessed 07 Dec 2018].

34 Farage MA, Miller KW, Ajayi F, et al. Design principles to accommodate older adults. Glob J Health Sci 2012;4:2-25.

35 Flesch R. A new readability yardstick. Journal of Applied Psychology 1948;32:221-33.

36 US National Library of Medicine. How to write easy-to-read health materials, 2017. Available: https://medlineplus.gov/etr.htm [Accessed 06 Apr 2019].

37 Chew LD, Bradley KA, Boyko EJ. Brief questions to identify patients with inadequate health literacy. Fam Med 2004;36:588-94.

38 Chew LD, Griffin JM, Partin MR, et al. Validation of screening questions for limited health literacy in a large Va outpatient population. J Gen Intern Med 2008;23:561-6.

39 Tong V, Raynor DK, Aslani P. Comparative user testing of Australian and UK over-the-counter labels and leaflets for diclofenac. Drug Inf $J$ 2018;52:38-48.

40 Wallace LS, Rogers ES, Roskos SE, et al. Brief report: screening items to identify patients with limited health literacy skills. J Gen Intern Med 2006;21:874-7.

41 Sarkar U, Piette JD, Gonzales R, et al. Preferences for selfmanagement support: findings from a survey of diabetes patients in safety-net health systems. Patient Educ Couns 2008;70:102-10.

42 Lewis JR. Ibm computer usability satisfaction questionnaires: psychometric evaluation and Instructions for use. Int J Hum Comput Interact 1995;7:57-78.

43 Grudniewicz A, Bhattacharyya O, McKibbon KA, et al. Redesigning printed educational materials for primary care physicians: design improvements increase usability. Implementation Sci 2015;10.

44 Perrier L, Kealey MR, Straus SE. A usability study of two formats of a shortened systematic review for clinicians. BMJ Open 2014:4:e005919.

45 Bangor A, Kortum P, Miller J. Determining what individual Sus scores mean: adding an adjective rating scale. $J$ Usablility Stud 2009;4:114-23.

46 O'Brien BC, Harris IB, Beckman TJ, et al. Standards for reporting qualitative research: a synthesis of recommendations. Acad Med 2014;89:1245-51.

47 Staniszewska S, Brett J, Simera I, et al. GRIPP2 reporting checklists: tools to improve reporting of patient and public involvement in research. BMJ 2017;358:j3453.

48 Tong V, Raynor DK, Aslani P. Developing alternative over-the-counter medicine label formats: how do they compare when evaluated by consumers? Res Social Adm Pharm 2018;14:248-61.

49 Tong V, Raynor DK, Aslani P. User testing as a method for identifying how consumers say they would act on information related to overthe-counter medicines. Res Social Adm Pharm 2017;13:476-84.

50 Pratt M, Searles GE. Using visual AIDS to enhance physicianpatient discussions and increase health literacy. J Cutan Med Surg 2017;21:497-501.

51 Tannenbaum C, Martin P, Tamblyn R, et al. Reduction of inappropriate benzodiazepine prescriptions among older adults through direct patient education: the empower cluster randomized trial. JAMA Intern Med 2014;174:890-8.

52 Wilson MG, Lee TC, Hass A, et al. Empowering hospitalized older adults to deprescribe sedative hypnotics: a pilot study. J Am Geriatr Soc 2018;66:1186-9.

53 Jarernsiripornkul N, Phueanpinit P, Pongwecharak J, et al. Development and evaluation of user-tested Thai patient information leaflets for non-steroidal anti-inflammatory drugs: Effect on patients' knowledge. PLoS One 2019;14:e0210395.

54 Yamamoto M, Doi H, Yamamoto K, et al. Adaptation of the European Commission-recommended user testing method to patient medication information leaflets in Japan. Drug Healthc Patient Saf 2017;9:39-63. 